Sociedad Botánica de México

\title{
Dịstribución del Género Podocarpus en México
}

\author{
Por el Dr. Aaron J. SHARP, \\ de la Universidad de Tennessee.
}

En mi primer artículo sobre Podocarpus (Boletin núm. 4 de esta Sociedad, pp. 17 y 18) sufri error al decir "el autor tiene la impresión de que todos representan la misma especie botánica", pues estudios posteriores de este material llevados a cabo por Buchholz y Gray, demuestran que son tres las especies que se incluyen. En su monografia (1) se hace referencia a Podocarpus oleifolius. D, Don en la pág. 139. a Podocarpus Matudae Lundell en la 131 y a Podocarpus Reichei Buch.y Gray, descrito por primera vez, en la página 131.

La determinación de mis ejemplares debe quedar como sigue: El ejemplar núm. 46286, de San Luis Potosi es $P$. Reichei.

Los ejemplares núms. 45338 y 45339 son $P$. Reichei, de la localidad típica en Puebla.

El ejemplar núm. 46150, de Veracruz, es $P$. Reichei.

El ejemplar núm. 46326, de Oaxaca, es $P$. oleifolius, lo mismo que el de la Sierra de Las Minas, en Guatemala. El ejemplar núm. 45987 de Chiapas, es $P$. Matudae.

Es interesante hacer notar que este lugar se encuentra en el centro de la distribución (véase mapa) citado para $P$. oleifolius.

(1) Buchholz, J. T. and Netta E. Gray. A Taxonomic revision of Podocarpus, IV. The American species of Section Eudocarpus, subsections C. and D. Jour. Arnold Arboretum. April 29: 123-151. 1948. 